\title{
elyRa
}

\section{Finitude e prospecção - gestos escriturais}

\section{Tiago Cfer \\ Universidade São Paulo}

Resumo: Reflexão sobre o espaço poético propiciado pela performance de agora. A partir da produção ensaística e poética de Mauricio Salles Vasconcelos, e com foco sobre dois trabalhos desdobrados de seu livro Ar livre, "Livro/Telefone/Rua" - uma ópera estenofônica - e "Ato/Ambulante", investiga-se o campo relacional que as dinâmicas do livro e dos eventos-performance vêm implementando entre literatura, filosofia, música, tecnologia, urbanismo, ecologia.

Palavras-chave: poesia; performance; filosofia; tecnologia

Abstract: Reflection on the poetic space provided by the performance of now. From the essayistic and poetic production of Mauricio Salles Vasconcelos, and focusing on two unfolded works from his book Ar livre, "Livro/Telefone/Rua" - a stenophonic opera - and "Ato/Ambulante", we investigated the relational field that dynamics of the book and the performance-events have implemented between literature, philosophy, music, technology, urbanism, ecology.

Keywords: poetry; performance; philosophy; technology 


\section{Princípio-Scratch}

O texto só vem agora, mas era anterior. Depois de uma performance ou ato de fala (leitura, entrevista, conferência ou mesmo aula) de Mauricio Salles Vasconcelos, sobrevém essa impressão: a materialidade complexa e quase indestrinçável de seus escritos passa para um plano de corpo ao vivo ainda não assimilável - e já para sempre excedido (Vasconcelos 2017: 73). Interessante é notar que a marca do que escapa ao dito ou ao escrito (voz/som aleatório/ruído) se faz em diálogo com dados da História presente - sob o signo dos primeiros anos 2000 .

Não há apelo do autor a uma lógica modelar, prolongada ou desenvolvida através de vínculos identificatórios entre a palavra escrita e a palavra falada. Não ocorre uma divulgação autobiográfica aí, mas movimentos de escrita numa laboriosa desarmação/reelaboração de si. Do livro ao ato jamais se observa um jogo de complementação ou justificação retórica mas, ao contrário, desdobramentos e suplementações que só ampliam o espaço orbital, orlar, díspar da palavra em seu seguimento à vida coeva dos objetos técnicos (para se falar aqui em sintonia com as focagens pioneiras de Gilbert Simondon acerca de uma era tecnificada, já instalada, constitutiva dos menores gestos cotidianos).

Nos escritos de Mauricio Salles Vasconcelos os modos de arquivar, diagramar e mapear a história de agora se sincronizam com o incipit de um outro tempo que emerge desde a guerra iniciada em setembro de 2001 - uma guerra para pôr fim à Guerra, diz Avital Ronell, numa reincidência tautológica dos mesmos alvos e motivos (por conta do terrorismo e de uma hegemonia quanto à ordem global). Não ao acaso, Vasconcelos estava realizando pós-doutorado em literatura/filosofia/tecnologia sob a supervisão da autora de Finitude's Score - Essays for the End of the Millennium, na New York University, exatamente no período de setembro de 2000 a setembro de 2001. Um dado curioso está em seu retorno, depois desse tempo na cidade-mundo onde se deu o desastre revelador do início do milênio, precisamente no dia 11/9/2001. As torres gêmeas do World Trade Center estavam sendo detonadas, quando o escritor/performer voltava para casa.

Toda essa convergência de pontos envolvendo performance/poética/pensamento demonstra um mecanismo de anotação que compreende um tempo definidor de outro 
critério de época, de datação histórica, posterior que é ao apocalipse teleológico há tanto projetado para o século/milênio por vir; tempo sem outra escatologia senão o tom do que vem, em um modo próximo à filosofia de Blanchot, e também de Agamben, em relação com uma futuridade já em instauração, misto de promessa e problematicidade, sem mais o toque de prenúncio/progressão.

Registra-se, então, um princípio sem retorno (ou uma an-arquia: ausência de princípio), pautado pela viralização/virtualização do conhecimento, da cultura, da ciência e do desastre. Advém dessas anotações uma escrita scratch sobre as ondas info do mondo tecno, em sintonia com o que Vasconcelos deixa destacado, num ensaio de 2002 sobre a filósofa norte-americana Avital Ronell - "Derivados da diferença - Estenofonia": "É como se à escrita não se acrescentasse a voz [...], o verbo como precedência ontológica [...]. E sim, o ruído, um suplemento e noise" (Vasconcelos 2002: 205).

Não há mais o que aguardar de uma ação escritural empenhada em teses englobantes, a fim de restituir a suposta autenticidade/originalidade da palavra, senão previsíveis e redundantes reverências prestadas à cultura oficial, em sua vontade de garantir e conservar um assento, um posto reprodutivo nas corporações do parasitismo discursivo.

A performance, no entanto, hoje atua num vetor de acontecimento indesviável do ato de escrita que a constitui e a antecede. O texto só ganha voltagem performativa se antes já engendrar um lastro producente, de veios não restituíveis à palavra concebida como letra validadora de um espaço reverente/referente à continuidade de uma imagem vigente do literário.

Eis o que ocorre com esse universo de performances que se dão tanto no espaço da linha de poesia (verso tomado como pauta experimentadora de recursos imagético/sonoros/conceituais) quanto em diferentes formas de cena e palco: um trabalho de linguagem - no contexto de uma cultura tecnocapital planetária - que não deixa interromper sua linha transitiva de relações criativas, culturais, históricas. Para além da determinação de um encampamento em algum nicho ou atrelamento sistêmico - mesmo aquele forjado por uma noção fechada de performance ou de espaço estrito do livro. Uma escrita em ato que conjura a virulência da linguagem. 
Visível se torna, nos dois últimos livros de poesia publicados por Mauricio Salles Vasconcelos, Caderneta-maquete (2016) e Ar Livre (2017), uma operação de registro que se utiliza dos muitos suportes de anotação/arquivamento (do lápis-caderneta aos dispositivos móveis, numa explicitação de tais processos no decurso dos textos). Assim, se imprimem e propagam-se as linhas cruzadas de uma arte que é, também, conhecimento em formação, em caminhada/mapeamento dos espaços da megalópole num tempo de globalidade que advém com a consolidação, já na cultura e na vida cotidiana do século $X X I$, de uma verdadeira cyberculture.

A estenografia, ao modo como Mauricio se dispõe a usá-la, numa captação e emissão - com toda uma ênfase nos gestos de recepção/recolha/registro contidos no escrever em diferentes formas de inscrição/notação - das muitas camadas que compõem o tempo que passa só agora - dando-se, vindo, envolto em amálgamas de fragmentos de corpos, vozes, sons, imagens -, proporciona aos poemas uma consistência tumultuosa. Estes se apresentam como pequenos dispositivos de produção, espinhas dorsais agitadas, impulsionadas por interferências e variantes discursivas que, de certo modo, dão um aspecto de flagrante/erradicação eletrizantes em face de situações e signos que irrompem e fazem uma espécie de debandada a cada página do livro, proporcionando um vivo, contínuo movimento para a captura imediata da escrita. É o que se observa no seguinte poema, "Série" (abertura do capítulo “Muzak (2003-2006)” de Ar Livre ):

As portas da maior cidade se oferecem à urgência/imagem Postais

Dentro dos cubículos de sexo, moradias sarah jessica parker Taxas sempre em alta, sob nomenclaturas/pós-metrópole, N.Y a nu de nenhum até logo, after hours

Entre corpos geografias trifases vírus em tempo real Implemento discursivo indireto

Do que está-por-vir e já é refém/um átomo

Cosmo à deriva cabe nesse loft como se seguisse Vozes

Senão teléfonos diversos enganchados nos seres silhuetas Contam epidemias públicas privês: 
Esperar por nada - abrir janelas e dias (retículas

Por pequenos gozos

Gosmas de hóstia, cápsulas indiferenciadas),

Acompanhando séries:

A enorme lufada de ar depois

Do parque e da casa, um sentimento

Absurdo, planetário, de estar por aí, respirando tudo

E bem (a pensar o "bem", radical-cifra),

A convite de um (como se fosse "off")

Continuum - voz vaga, volta,

Autorreplica - Indiscriminadamente, "confesso"

Estar bem, sob fiança

De um segundo do mundo

“De todo mundo" (Vasconcelos 2017: 68)

Essa intensidade poética acaba por conferir ao livro um frêmito, uma presença sempre atualizadora no que envolve captação. Observável é uma postura ao mesmo tempo atuante e receptiva, instigando o leitor a demonstrar, em suas investigações, que um tal objeto é da ordem do incessante, jamais deixa de vibrar. Nessa circuitação de atos de escrita e leitura, cada texto/livro/poema eclode como qualquer coisa que pode significar uma mudança na respiração (Celan 1996: 54), como se lê no discurso de agradecimento, feito por Paul Celan, ao prêmio Georg Büchner (1960).

A trama escrita-voz-livro-corpo em atuação suscita uma verdadeira circulação, um arejamento não apenas naquele que está evocando e disseminando a palavra. Poder-se-ia dizer que a performance apenas ressuma quando o ambiente e as formas de vida presentes, no ato, se transformam em fonte do acontecimento, ou seja, irrompem numa afluência ao evento em que se constitui a dimensão performativa da linguagem, já pulsante por escrito. Configurando-se numa espécie de ventriloquismo, tal como nota Ron Silliman no seu ensaio "After word: Who Speaks: Ventriloquism and the Self in the Poetry Reading", presente no livro editado por Charles Bernstein, Close Listening: Poetry and the Performed Word: "No event invokes the power of presence like a reading. The performer literally POPs off the 
stage and is the page from wich the words of the text emanate, if not actually from which the words themselves appear to have been inscribed" (Bernstein 1998: 373).

Assim, o autor vai se constituindo, em meio à truculência dos mercados negros de organismos e multidões em que se arrojam projetos globalizadores agônicos, enquanto traficante de sons e grafias, produtor ambulante de livros e enunciação livre. É o que se lê em "Ambulante (2006-2011), segunda parte do livro Ar Livre. Uma simples posição deambulante que segue abrindo signos, vias, prospecções ao tráfego semionáutico em www - a "confluir en una obra sin clara filiación, sin raíz profunda y sin nostalgia, como una visión positiva de la complejidad y el caos" (Mallo, 2009: 186). Uma espécie de pirataria dos signos de apocalipse e predição, de finitude e prospecção, instalada no contexto de agora há tantas eras anunciado/projetado, de modo a exercer uma espécie de vidência do presente.

\section{Heidegger na linha}

Torna-se perceptível desde "Para quê poetas?", texto de 1946 no qual Heidegger situa Hölderlin como precursor de uma viragem poético-filosófica no âmbito do "tempo da noite do mundo" (Heidegger 2012: 307-367), como aquele que "mais se expôs ao risco da linguagem" (ibidem), a emergência, no imediato pós Segunda Guerra Mundial, de uma escrita e de um pensamento desabrigados - apartados do lastro onto-antropológico ocidental.

Signo de um tempo sem origem nem destino, de uma lógica do excesso, a noite estancia uma experiência-limite das linguagens. Configura-se como campo de forças conjuntivas/disjuntivas, contrativas/expansivas, envolvendo o presente numa atmosfera ambivalente onde coexistem, em plano aberto e ao ar livre, imagens, memórias e referências arcaicas e atuais, dados provenientes de "todos os tempos", em confluência e disseminação numa ambiência técnica/tecnológica, maquínica.

Se no ensaio de Heidegger a linguagem ainda é compreendida como casa do ser, e o mundo um espaço interior que abarca a totalidade do ente, ficando reservado à poesia o acesso a essa interioridade como modo de salvaguardar o destino do homem (a poesia ainda concebida como senha ontológica), observa-se em "Para quê poetas?", contudo, antes desse recuo a uma função essencialista, pastoral do escrever e do pensar que figura no desfecho 
do ensaio, a apresentação de um movimento decisivo à poiesis que veio se configurando na passagem finissecular, milenar. Trata-se do contato, através da poesia de Hölderlin e Rilke, com uma espacialidade analítica limítrofe. Para Heidegger, o poeta do tempo indigente, da noite que sucede a morte de deus, é aquele que, "no círculo mais vasto da esfera" (idem: 345-347), torna-se capaz de produzir uma linguagem da virada, transformando o desamparo em aberto.

A partir dessa manobra psicotopográfica, realizada na crista dos séculos, iniciadora de uma época na qual o acúmulo histórico passa a ser recepcionado, então, desde uma posição zerada - espécie de infância do mundo -, esvaziada dos critérios que respaldavam a intimidade humanista (a domesticidade filosófica fundada pelas noções de origem/fim, original/cópia), a poética contemporânea vem se realizando. Não mais em correspondência a um mundo dado - como supunha o filósofo de Ser e tempo -, mas em processos de individuação sem substância, na produção/profusão de mundos. Aliás, Mauricio Salles Vasconcelos, no ensaio Exterior. Noite - Filosofia/Literatura, publicado em 2015, demonstra que a (não) obra de Blanchot, matriz dessa era em descortínio desde a segunda metade do século XX, propaga-se a partir de tal abertura.

$\mathrm{O}$ ato de escrever, ou a escrita em ato, convoca uma comunidade de amigos e amantes desconhecidos, em formação. Conflui com a circulação de mercadorias e culturas pelo mercado mundial, com o alargamento dos limites de uma erotologia global num projeto de mundo hiperinclusivo de usuários de todos os segmentos da escrita remetentes/destinatários de sms, e-mail, informação em rede, etc. Tal deambulação vibra dentro de um circuito de trocas intermináveis, características do comércio em vigor, sinalizado por simultaneidade de bens transnacionalizados e, nos momentos e movimentos, timbrados pelo traço do tráfico/pirataria/cópia/reprodução deliberada dos valores da hora na órbita mundializada em que tudo, todas as pessoas e seus objetos transcorrem. A figura do ambulante se torna eixo de uma captação/captura performativa de um tempo (agora) que escoa. " "Você" não está sozinho, ficção fabrica suas próprias faces,/ Pontilha o nome sujeito menos imaginado// Agora/ Aleatório, Ambulante/ "Só Se For Agora"// - Só se gora agora/ Não-Mais" (Vasconcelos 2017: 64). 
Já bem instalada, ao menos desde o começo da década de 1990, com a invenção da $w w w$, essa comunidade - em fomentação há quase duas décadas já transcorridas neste milênio -, figura como uma mutação, em inter-relações díspares (sistemas abertos e inacabados decorrentes das ciências do caos), dos círculos de amigos humanistas apresentados no livro-carta ao mundo de Sloterdijk, Regras para o parque humano: uma resposta à carta de Heidegger sobre o humanismo:

Na perspectiva erotológica, a hipotética amizade dos escritores de livros e de cartas com os receptores de suas mensagens representa um caso de amor à distância - e isto exatamente no sentido de Nietzsche, que sabia que a escrita é o poder de transformar o amor ao próximo ou ao que está mais próximo no amor à vida desconhecida, distante, ainda vindoura. A escrita não só estabelece uma ponte telecomunicativa entre amigos manifestos vivendo espacialmente distantes um do outro no momento do envio da correspondência, ao que não está manifesto: ela lança uma sedução ao longe, uma actio in distans, no idioma da magia da antiga Europa, com o objetivo de revelar o amigo desconhecido enquanto tal e levá-lo a ingressar no círculo de amigos. (Sloterdijk 2000: 9-10)

Dessa perspectiva, cada evento-performance de linguagem, hoje, vem marcado pela força de um começo heteróclito na medida em que se oferece como "Segunda-mão" (é o título de um poema de Ar Livre) à criação do universo, um modo de suscitar/suplementar a explosão de onde teria vazado a fonte dos acontecimentos. "Um livro para ser aberto (modo de transporte)/ Em todos os instantes/ Estações um efeito/ De capa e leitor,/ Letras se miram/ Para fora do âmbito estritamente escrito" (Vasconcelos 2017: 59). E os aparatos tecnológicos, as máquinas de todos os tipos, parecem ser suficientes para nos alojar numa espaciotemporalidade de mundo permanentemente nascente, no agora que escapa aos calendários e proporciona à experiência uma finitude na qual cada dia se faz como sucessão do primeiro/último dia, em toda sua abundância e força destruidora irrepetíveis.

O fazer poético é testemunha de que seguimos reivindicando para o gozo pleno, uma vez que queremos criar zonas de aproximação nas quais nossas estranhezas e distâncias se tornem o motivo (sem fundo) da comunicação. Afirmar nosso comum desabrigo (despertencimento e desentendimento) como modo de experimentar outras faces e dimensões da (co) presença. Estar-juntos num ambiente onde a memória da queda e o 
anúncio do apocalipse foram banidos. Descobrir-nos, sem culpa, em gestos por escrito. É o que se lê no poema "Parque temático":

\author{
Queremos estar - logos insone - \\ Ser homens feitos, nomear o que \\ Não se vê - a origem e a \\ Correnteza exangue, à solta - \\ Dentro de um panorama, ou então, \\ Um parque, um cessar-fogo \\ A qualquer hora, pelas tantas fontanas
}

Sob o contínuo rumor do fim da vida (idem: 98)

Assinalando um sentido expansivo de poiesis, através de uma escrita que se dá no acúmulo de instantes, na sucessão de auges mesclados pelo excesso de imagens e sons em difusão no planeta tomado por objetos técnicos e multidões, a poética de $\operatorname{Ar}$ Livre se sintoniza, em outro século/milênio, décadas depois do testemunho dado pela transmissão radiofônica de Artaud, em 1947 - Para dar fim ao juízo de Deus -, com a emergência enunciadora de uma apreensão amplificada do universo após grandes, coletivas confrontações de forças. Realiza-se para fora de uma entonação peremptória, encerrada no âmbito dos padrões do "poético", a serviço de uma linguagem monológica (dentro do esquadro do juízo/palavras-de-ordem sobre o atual estado de coisas).

Movida pelo toque performativo, a escrita de Mauricio Salles Vasconcelos - que desde seus primeiros livros está ligada a experiências em outras mídias, como sua atuação, na Rádio MEC/Rio de Janeiro, no período de 1979-1985, com a produção dos programas "Contistas brasileiros" e "Momento teatral", contando este com performances/leituras conflui com o mundo-ovo artaudiano (como o definiu Deleuze). Encontra-se em grande afinidade com o "abrigo-mundo" dos newyorkaises de Hélio Oiticica. Ou ainda, estabelece vínculos com a topologia poético-relacional de Christophe Tarkos, autor performer por excelência, que chega a apreender o universo contemporâneo como uma "máquina de lavar" - objeto maquinal diluidor das linhas divergentes e plurais de criação. Numa vertente muito próxima da esferologia concebida por Peter Sloterdijk, propõe a abertura de 
semióticas mistas, heterogêneas, capazes de captar a plurivocidade planetária para além de qualquer ordenação globalizadora.

Mostra-se decisivo para o trabalho que o autor vem desenvolvendo neste século incluindo aí sua produção ensaística - o contato com ares provenientes de sua vivência em Nova York, onde Mauricio Salles Vasconcelos estreitou contato com diferentes performances musicais, visuais e poéticas, de Joan La Barbara a Vito Acconci, de John Ashbery a Robert Ashley. Surgiu de tal ambiência a criação da ópera estenofônica "LIVRO/TELEFONE/RUA", inspirada em The Telephone Book, de Avital Ronell.

Concebida entre 2000 e 2001, a ópera está presente no livro Ar Livre, onde se observa uma escrita em curso nas adjacências da cidade, na qual o texto vem se dando já como performático, traçando desenhos e movimentos espaciais, extraindo música da fusão palavra/voz. Ouve-se na atmosfera da realidade pulsante, presente, uma polifonia de sons toques celulares, vozes e ruídos que atravessam o ar das cidades, sinalizando uma espécie de "Horda de Holderlin" (como diz o poema de mesmo nome). Não à toa, as derivações do signo aéreo jogam com o aleatório e o que há de antecipação (rumor, presságio, mixagem e som/sopro), quando se lida com as imagens de fonte-fim, próprias de uma época como a de agora, que vêm figurar logo no começo do poema de abertura, "Recepcionista (scratch conversation)":

Eu sou a recepcionista

Sou eu mesmo quem atende

Em nome de ninguém (Jingle)

Imediata mensageira de "Tudo

\section{O que se conhece e é transmitido na hora}

Qualquer dito logo se insere"

Em cada livro a

Agenda aleatória

Carregada por todos onde

Quer que desapareçam 
Eu sou a recepcionista, a mais pura ouvinte

(aquela jamais vista)

Tão-somente ouvidos

Hospedeira de vozes EM ATENÇÃO A VOCÊ

Sou sua, um VELHO TESTAMENTO,

um verbo ambulante para sempre e sempre

Sem juízo e sem volta - Sou, ao contrário,

Você mesmo: sua voz ausente

Sempre disponível (Refrão da recepcionista para uso de scratch)

(idem: 84 e 85)

Deflagra-se, com a espacialidade ondulatória que se implementa a partir da mesa da telefonista, como bem formula Avital Ronell, the walking switchboard (uma tecnologia nada funcionalista, marcada pelo dado performativo inseparável da presença e uso de toda tecnologia, de todo aparelho/aparato), uma topografia heterodoxa. Interessante é notar que Avital Ronell, em The Telephone Book, atualiza um diálogo com Heidegger de forma a romper as barragens criadas entre criação e tekhné, colocando em primeiro plano a figuraconceito da Recepcionista/Telefonista como operadora-chave de existência, linguagem e pensamento em uma era de alta tecnologia. Justamente, o traço que mais se destaca é de uma performance (voz - palavra - corpo) suspenso pelo booth/book telefônico.

"LIVRO/TELEFONE/RUA" ocorre como poema de vozes que atravessam a janela da casa concluída pela filosofia de Heidegger. Vozes vindas do exterior, via plugagens tecnológicas, reunindo-nos de volta à casa compreendida como espaço urbano, mundializado (para além dos estamentos globalizantes dos blocos geopolíticos, a vida/arte/cultura da mundialidade se fazem através de congraçamentos tão heterogêneos quanto imediatos), em celebrações poéticas, artísticas, musicais que acabam destruindo a domesticidade, o abrigo (noção de casa como espaço privativo).

Desde essa morada - aberta, desmurada, destelhada - é que Mauricio Salles Vasconcelos faz uma chamada à tradição. Mas, se nos atemos às proposições do filósofo do fim da metafísica de que através da tecnologia o ser retira-se definitivamente de nosso 
meio, e que com o uso das máquinas os homens se descaracterizam à medida que são envolvidos por uma nuvem sem sinal, quem é que está do outro lado da linha?

\section{Novas regiões do mundo}

Aquelx para quem ainda não há um rosto. O que explica o incessante encaminhar-se da poesia para o desconhecido, sua obsessiva atração pelo enigma - ou, para dizer com o livro do desastre de Blanchot, pela ausência (que não constitui uma resposta) de questão? Uma maneira de se retirar (da ordem) do mundo na abertura do mundo.

Enquanto pulsa numa espécie de ondulação - deriva e devir da linha poética sem remissão à simples disciplina-literatura -, na mudança de um estado para outro das coisas o diverso, o díspar -, o poema é compleição do impossível e impensado, disto que está atrás do absolutamente outro. Ou a recepcionista (você mesmo: sua voz ausente): uma "desestabilização do remetente": "Eu sou o signo ao vivo// Invisible Partner// Inner Walk (...) Sempre em outro lugar que não aqui,/agora e/ou nunca" (idem: 86).

Feito uma voz vinda do outro lado da linha, o projeto musical LIVRO TELEFONE RUA se apresenta por meio de uma operação que consiste em arrastar a palavra filosófica/poética de seu estado gráfico para a vibração sonora. Trata-se de, a partir de uma travessia vivamente integrada a um projeto performático, desterritorializar o livro em sitehospedeiro de ópera/música estenofônica. (É o que pode ser ouvido em http://www.marcussiqueira.com/livro-telefone-rua - senha: livrotelefone -, site criado pelo compositor erudito contemporâneo Marcus Siqueira, parceiro de Vasconcelos no projeto poético-cênico-musical).

Tal procedimento acaba por desestabilizar as relações automáticas, recitativas, declamatórias, as hierarquias entre vocalização e palavra textual, ressituando a linguagem em sua potência motriz, viral, dispersiva, sem relação matricial com um todo orgânico ou uma condição original (seja o livro seja como repositório da esfera verbal, seja a telefonia como referendo eminentemente técnico de matrizes sonoras/tecnologias acústicas ou eletrônicas). Isso está enunciado na primeira faixa do disco, "Intro: Irrompimento": "Então/ Irrompo no meio de um movimento (...) Todo livro é tomado de fora/ Célula de uma conversação interrompida/ Revolta e desdobrada em um Musical" (Siqueira 2017: faixa 1). 
LIVRO TELEFONE RUA testemunha a força viva de uma escrita em ato/cena - dentro e fora do estritamente escrito. Através de recursos provenientes da estenografia e da estereofonia (escrita digital, música erudita/eletrônica), faz circular - na medida em que cria entrelaçamentos entre livro, telefonia, rua - filosofia e literatura para o exterior de qualquer suposto domínio. A própria disposição da ópera em site, ao converter a cosmotécnica contemporânea conceituada nos poemas do livro em faixas musicais acessíveis de qualquer lugar, afirma um vínculo inseparável entre livro de poesia, tecnologia e performance. Retira, assim como ocorre em The Telephone Book, de Avital Ronell, "o instrumental tecnológico de sua órbita encerrada de comunicação, da mera acoplagem ao mundo do capital como fundo panorâmico de épocas e culturas, para reconfigurar projetos de escrita" (Vasconcelos 2015: 144).

O livro passa então a ser concebido como meio propagador de ações/modos de pensamento/escrita, como dispositivo tecno em toda sua polivalência - conexional, relacional. Um objeto poético e performático no mais amplo sentido. Fonte distribuidora de novas imagens e sonoridades que vêm contracenar no jogo infinito das mutações figurais e tecnossemióticas. "Como se tudo estivesse em um crescente engendramento: o livro (receptáculo da memória) e seu jogo (ao vivo) no passar de um tempo, e de uma época assinalada simultaneamente pela finitude e pela prospecção", escreve Mauricio Salles Vasconcelos na apresentação de Minha vida (Hejinian 2014: 8) - edição brasileira cuja tradução foi realizada pelo escritor.

Compreende-se, assim, tekhné e linguagem como repetição do evento desde sempre existente - efeito dissimulante da matéria-prima depreendida como precursora sombria -, das sínteses químicas às estratificações geológicas, das mãos em negativo de Gargas às máculas pictóricas de Cy Twombly, dos incorporais estoicos aos cut-ups de Burroughs. Essa seria uma via para explicar o modo como Vasconcelos apreende, por exemplo, a América no poema-música-filosófica de mesmo título. Observa-se aí uma visada arquipélica, uma cognição em relação expansiva com o mundo, em sincronia com a filosofia da relação do escritor antilhano Édouard Glissant. Algo capaz de formular imagens e sonoridades da violação e extorsão impostas ao bloco continental até então imperceptíveis, por exemplo, ao universo da MPB ou da sociologia acadêmica - sempre atulhado de redundâncias em nome 
do nacional e do corporativado lugar-comum. "América opera com lógica de crise/ Balística/ Depressão/ Stress/ Emergência// América é um nome-mulher em toda sombra de filho/ 0 mais distante, em revolta ou sempre perdido" (Siqueira 2017: faixa 3).

Essa intensificação perceptiva, decorrente do repositório cultural que é o meio do autor - livros, notas, estudos, ensaios, criações poético-fictivas, entrevistas, aulas, performances - transforma o indivíduo que lê, escreve, publica, performa, em corpo aberrante. Um monstro híbrido, multifacetado, crioulizado, através do qual novas regiões do mundo (imaginárias e concretas) serão desbravadas e apresentadas através de um trabalho de linguagem que dá-se em corte com as características poéticas modernas e pós-modernas. Não mais se vincula a um projeto radicalizado nas origens da arte e da sociedade a fim de restituir-lhes o elo perdido (modernismo), nem ao projeto de uma coexistência pacífica e estéril de culturas reificadas (multiculturalismo), bem ajustadas à rotulação, à ideologia do pertencimento, ao fluxo uniformizador da globalização (pós-modernismo).

O artista/autor no século XXI insurge então num projeto desatrelado desses pressupostos (modernos e pós-modernos) que determinam os circuitos do mercado. Dispõese como produtor de itinerários na paisagem dos signos. É o que sugere Nicolas Bourriaud com o conceito de altermodernidade, formulado em seu livro Radicante: "O altermoderno é para a cultura o que a altermundialização é para a geopolítica, ou seja, um arquipélago de insurreições locais contra as representações oficiais do mundo" (Bourriaud 2011: 189).

Não ao acaso, emerge de modo nomeado, no disco LIVRO TELEFONE RUA a figura do monstro. É a partir do chamamento à fonte-mãe-mulher que a recepcionista e a América se tornam porta-voz e solo ("A mãe chama primeiro/ E a criança é o que vem" - está na faixa "A chamada"), num popsong ("Monster") presencia-se o surgimento de uma voz informulada (Siqueira 2017).

Nota-se a fulguração de uma imagética tendo como eixo a inoperância, essa que subjaz à noção tão presente de finitude ("Finitude's Score", já frisava Avital acerca do milênio em passagem e dissolução do ideário progressivo). Fulguração que, inclusive, podese observar nos filmes de Jean-Luc Godard, especialmente em Week-End, tal como Mauricio Salles Vasconcelos apreende, em seu livro Jean-Luc Godard: história(s) da literatura, um modo de fazer cinema fora do enquadramento daquilo que se entende por "cinema 
temático, organizador do crash e do caos", numa composição da tela na qual deixa de haver busca de sentido original e destinação. "Não há fundo, nem pano de fundo", mas "mostração/monstruação de signos histórico-culturais em estado de choque": "Nada se ordena fora do interesse, segundo o diretor, em filmar e dizer os "monstros" produzidos pela civilização, na contracorrente de uma "visão" política organizada" (Vasconcelos 2015a: 107). Justamente, se observa nesse núcleo composto de inoperância/finitude a infância lançada através dos tempos ao que vem em sua dimensão de apocalipse que se alastra na inexistência do Juízo Final, sem outra escatologia senão o tom do "vem". Um chamamento ao revés do teleológico, como no Blanchot relido em Parages, de Derrida, e n'A comunidade que vem, de Agamben, com toda uma ênfase em um vir-a-ser sempre em curso a despeito da ênfase na meta, no inaudito, na promessa de futuro enquanto fim.

\author{
Monster Monster \\ Path of the unborn \\ Answer Answer over my proper voice
}

Something under the skin

Sky Projections: Nests or Nets

Inside Lines

Monster Monster

No Ecology or Reflection of Civilization Terror

No Direction - Simply Another Ear

Monster Monster

Voice Stream

Voice Stream anda No More

Remote Control - Makes appeare Reactors Unthinkable Places

Gardens of Zumbis and Zens

Oracular source

Oracular source (Siqueira 2017: faixa 4) 
Um novo cenário de ação da palavra - escrita, vocalizada, instrumentalizada em música e noise - se abre através do livro concebido como espaço de trânsito/cruzamento polifônico que envolve as diversas áreas do saber. Do Livro ao Telefone, endereçando-se, em lugar de outro receptáculo/meio/sistema-de-informação, no plano aberto, paradoxalmente nada pacífico, não-dado, ao espaço da rua enquanto ponto de agregação e inacabamento, de uma extensão irrefutável de pertença e partilha no coletivo, no sempre divergente trânsito de uma realidade "em passagem", na órbita da caminhada e da corporalidade.

A ativação de projetos de escrita geminados, operados pela figura do monstro que lê/escreve e modula variadas linhas de ação da linguagem, se dá como enfrentamento às imagens de mundo projetadas apenas ao que é rentável. Como intervenção cultural nos espaços urbanos despotencializados pelos ideais do consumo de bens (a rua tornada outlet), capaz de gerar zonas ainda não definidas, alternativas de atuação, tal como apreende o espanhol Agustín Fernández Mallo, numa confluência da Land art com as proposições situacionistas, a pós-poética se insurge como encontro de extrarraios:

la postpoética busca e (sic) investiga todo un nuevo campo de acción en el que acometer sus obras, y éste no es una zona puramente física, sino el extrarradio que se forma cuando se juntan la poesía tradicional/ortodoxa con el corpus científico, artístico y social contemporáneo, el espacio de fusión entre ambos. (Mallo 2009: 97)

Novas regiões do mundo passam a ser experimentadas, então, para lá dos critérios de verdade (falso/real, artificial/natural, cópia/original) que legitimam o capitalismo corporativo, através do trânsito produzido pelas ações poéticas/performáticas. Ao deslocarem objetos e conteúdos de contextos segmentados a outros, não formados, em fomentação, estas práticas desbravam novas zonas poiéticas - o escritor/performer não como intermediário, mas produtor de novos meios, sublinha Franck Leibovici em Des documents poétiques (2007). Acionam elos não-lineares entre os sentidos, a sensorialidade do corpo humano e a viabilização dos transportes, das mediações técnicas.

LIVRO TELEFONE RUA abre-se para um corpo vivo de fala - dos meios de emissão e recepção do livro, passando-se pelo telefone em abertura para a caosmose polifônica das ruas mundializadas. Sem perda da remissão e reconfiguração do livro, oraliza em suas faixas 
um espaço para a poiesis à altura de uma época de alta tecnologia. Implementa, assim, uma concepção de literatura móvel - de acordo com as proposições de Mallo, em seu livro Blog$U p$-, justo enquanto expõe a expansão semântica no momento em que ela se realiza - por escrito, vocalizada, em enunciação livre.

\section{Isso é um assalto: ATO/AMBULANTE}

A performance ATO/AMBULANTE (Vasconcelos 2017i), realizada por Mauricio Salles Vasconcelos no lançamento de Ar livre, dia 7 de abril de 2017, na Biblioteca Roberto Piva, centro de São Paulo, traz à cena o Ambulante. Condensando indigência máxima e abertura para outro plano/mutação, em sintonia com figuras desterradas em módicos comércios e reincidente mendicância pelas ruas do mundo global de hoje, este personagem funciona como transmissor sígnico através do qual se performativa um gesto para fora dos limites prescritos/infligidos à realidade. Surge como expressão de um mundo possível.

Feito um corpo/ato de pensamento/escrita, o ambulante quer dizer, aí, aquele que vem. Tal como o suplicante abordado por Blanchot em A conversa infinita, ele compreende o seguinte dilema: "todo recém-chegado propõe uma verdade que não se deve pôr porta afora; mas, se a acolhemos, quem sabe até onde ela nos conduzirá?" (Blanchot 2007: 24).

No entanto, assinala o autor de A conversa infinita, o rito da súplica, em toda sua ambiguidade, está relacionado à busca grega da medida: "quando o poder ultrapassa o limite, comprometendo o equilíbrio, um outro poder que inverte a situação de força intervém em favor do homem sem recursos" (ibidem).

Para lá do dictum adorniano de que "depois de Auschwitz seria bárbaro escrever um poema" (Adorno 1998: 26), a vergonha de ser um homem que experimentamos em situações extremas torna-se, em ressonância com Deleuze e Guattari, um poderoso motivo à criação. Como o animal que rosna, escava o chão, convulsiona para escapar ao ignóbil, a filosofia e a arte, segundo os autores de $O$ que é a filosofia?, fazem apelo a uma forma futura, invocam uma nova terra e um povo que não existe ainda (Deleuze/Guattari 1992: 111-146).

Assim como Artaud escrevia para os analfabetos, Glauber Rocha fazia filmes para os sem-terra (que, aliás, ainda não haviam se consolidado em "movimento"), MSV performa 
para os ambulantes. Em tom de súplica e chamamento, seu personagem entra em cena carregando um saco plástico preto enquanto profere palavras aleatórias das quais emerge um refrão em jogo entre trampo/Trump/trapo.

\author{
Me dá um trampo! \\ Trampo vem aí! \\ Eu quero um trapo! \\ Trampo vem aí pra fazer arrumação na Praça Roosevelt, onde \\ tem muita arte e sexo pelas bordas. É preciso deixar tudo arrumado \\ um dia que seja quando Trampo passar pelos cacos, pelos cracos \\ Do Centro da Cidade Maior do Continente. Ele passeia pelo Crack. \\ Trampo é trapo. \\ Trapo ambulante. \\ Não quero nenhum trapo por aqui. \\ Não quero nenhum trampo. \\ Não quero o que virá (trampo trapo). (Vasconcelos 2017i)
}

O ambulante retira do saco preto uma massa de pano e a acolhe no colo. Ergue o trapo e o oferece ao público ali presente. Comercializa o bebê ausente num gesto entre a mais dolorosa gravidade e o tom deliberado de farsa. Abandona o pano/bebê, deixando-o exposto ao público, dando sequência a uma leitura do livro em lançamento.

O poema intitula-se "Bebê": "Muitos o veem dormindo - dromomania -, exceto ele conhece/ O público, de onde (diante) o fio de vida se desnovela e engloba -/ O futuro será rumor - Voz locutora recita as placas, as paradas..." (Vasconcelos 2017: 57).

Se por um lado a criança que vem está sempre sob a ameaça de ser capturada e reificada, tornada modo de existência para-o-mercado, domesticada pela superdeterminação informacional/comunicacional que pretende imantar o tempo, por outro ela jamais deixa de ser o signo que nos arrasta para fora desses domínios. Firma-se, assim, como acontecimento (aquilo que já não é e ainda não é) que não cessa de estremecer nossos limites com sua presença de nascimento/morte ao infinito.

A criança: iminência do que é destituído de imagem e rosto; possibilidade/suspeita de um mundo assustador, do qual os únicos vestígios de expressão que nos chegam são o 
choro e o grito. "Não há como dar crédito - ninguém, nunca -,/(Nenhuma crença)/ Ao bebê trazido/ Extemporâneo à luz/ Do dia" (idem: 58).

Oriunda de um longo e amplo mapeamento revelador de um sentido renovado de História Cultural - História compreendida através de diferentes signos e campos do conhecimento -, a marca-matriz de chamados de voz/emissões de dispositivos pluraliza-se em uma nítida dispersão. Indica história e cultura em um vivo corte com configurações dadas, nascendo de posteriorizações colhidas numa multiplicidade de referências/experiências de ser e durar no tempo. É o que pode ser lido no seguinte enunciado - desdobrado de Rousseau, Heidegger, Bataille, Blanchot, Derrida e Ronell: “A mãe chama antes, mas só ecoa depois. Bem mais tarde, a ressonância e a conquista da voz se efetuam. Prepondera a linguagem, na anterioridade do apelo materno, primordial" (Vasconcelos 2015: 159).

O que mobiliza a literatura provém do ímpeto de um saber concebido pela dinâmica de um não-saber. Justamente, o que define toda performance - um plano mínimo de arte/conhecimento exposto à sua prova viva de gestualidade e ato.

A dimensão escritural se dá, portanto, em atendimento a um chamado plural, irreconhecível. Entre tudo o que já está escrito e tudo o que ainda resta por escrever. Emergências e ressurgências, qual um título de Michaux.

Sobre esse infinito do sentido (flagrado por Blanchot) anotamos e registramos nossa passagem pelo tempo que acontece bem (e somente) agora, em atrito com as forças designadoras do presente. Ou seja, através desse gesto (conceptivo, performativo por excelência) a literatura irrompe entre nós como o que não deixa de ser, enunciação ancestral e insurgente, proliferante, irredutível a uma origem/centro/unidade emissora. "A literatura: sem aparente razão-de-ser, existindo como se não houvesse mais" (idem: 362).

O ambulante, então, performativa esse modo de proceder por errância da literatura. Numa troca de máscaras-personae que, de certo modo, evoca a deambulação delirante pelas metrópoles globalizadas, abordada em filmes como Cosmópolis (Cronenberg) e Holy motors (Carax), o mendigo metamorfoseia-se em Assaltante: "'eu não falo por mim'// eu preciso agora 'só se for':/ estou pronto// passe tudo logo'” (Vasconcelos 2017: 62); depois em Atravessador: "Tomar a droga é (e)/ Atravessar o centro - A caminhada não se dissocia 
do tráfico/ Oculta um homem entrado em idade, na raiz da droga/ Disseminante/ Há um jovem a mais, um reincidente (contato cel secreto)" (idem: 55).

Então o Mendigo/Assaltante/Atravessador retira livros (do próprio autor) do saco preto e espalha-os pela sala da biblioteca onde encena. Reabre Ar livre. Leitura do poema "Segunda-mão": "O que acontece quando você lê/ Em espaço comum, coletivo?/ Anota o dia, a multidão da história?// Um livro para ser aberto (modo de transporte)/ Em todos os instantes..." (idem: 59). Transforma-se em Tatuador, depois em Buda.

Após a leitura que encerra o ato, o Ambulante/Buda cobre-se com o saco de plástico preto para ficar ali, exposto, à venda, para o "olho da rua". Um corpo ao vivo e já para sempre excedido. Tudo então reincide aí, no ar: remate aberto ao infinito. $O$ texto só vem agora, mas era anterior.

Do silêncio que se estende pela cena, irrompe a intuição de que sem o simultaneísmo dos diferentes nômades/passantes/habitantes das cidades e dos mais impensáveis lugares inexiste mondo tecno - desempenho multimediático de linguagens à altura de seu dimensionamento planetário. É o que deixa assinalar esse elemento móvel, transitório, crescentemente coletivo de informação/conexão na órbita das plugagens telemáticas. Enfim, parece não haver amplificação do escopo da tecnologia sem o dado da performance.

À noite. 7 de Abril, 2017, Biblioteca Roberto Piva - Centro de São Paulo. Um assalto aos limites entre livro, escrita e universos de linguagens, orbitados num plano vivo de corpo/voz, modula-se em variação sempre surpreendente. Figuras e faces tomadas pelo performer/poeta seguem o rastro-Ambulante

BUDA DOS LIVROS

Fique com este livro - De qualquer

Modo mesmo

Sem moeda de troca

Diz o Buda recém-empossado

Da seita à rua dos mais altos congestionamentos

"Se não há tempo hoje

Para a leitura dentro de 2, no mínimo,

Anos, o senhor encontrará 


\author{
O texto de agora" feito posterior - \\ Um fato, dado externo, \\ Alheio até ser pessoal indício - \\ À procura de mim "Apenas \\ Pela minha pessoa, exatamente \\ Tal como acontece agora", \\ Leve o livro acabado Há milênios \\ E depois confirme \\ Estarei aqui neste mesmo \\ Ponto (De volta). (idem: 45)
}

\title{
Bibliografia
}

Adorno, Theodor (1998), Prismas, tradução de Augustin Wernet e Jorge Mattos Brito de Almeida, São Paulo, Ática.

Bernstein, Charles (1998), Close Listening: Poetry and the Performed Word, New York, Oxford University Press.

Blanchot, Maurice (2007), A conversa infinita 2: a experiência limite, tradução de João Moura Jr., São Paulo, Escuta.

Bourriaud, Nicolas (2011), Radicante: por uma estética da globalização, tradução de Dorothée de Bruchard, São Paulo, Martins Fontes.

Celan, Paul (1996), Arte poética: O meridiano e outros textos, tradução de João Barrento e Vanessa Milheiro, prefácio e notas de João Barrento, Lisboa, Edições Cotovia. 
Deleuze, Gilles / Félix Guattari (1992), o que é a filosofia?, tradução de Bento Prado Jr. e Alberto Alonso Muñoz, Rio de Janeiro, Editora 34.

Heidegger, Martin (2012), Caminhos de floresta, tradução de Irene Borges-Duarte, Filipa Pedroso, Alexandre Franco de Sá, Hélder Lourenço, Bernhard Silva, Vitor Moura, João Constâncio, Lisboa, Fundação Calouste Gulbenkian.

Hejinian, Lyn (2014), Minha vida, tradução de Mauricio Salles Vasconcelos, São Paulo, Dobra Editorial.

Leibovici, Franck (2007), Des documents poétiques, Marselha, Al Dante.

Mallo, Agustín Fernandez (2009), Postpoesia: hacia un nuevo paradigma, Barcelona, Anagrama.

Ronell, Avital (1989), The telephone book. Technology, Schizophrenia, Electric Speech, Lincoln, University of Nebraska Press.

-- (1994) Finitude's Score. Essays for the End of the Millennium, Lincoln e Londres, University of Nebraska Press.

Siqueira, Marcus (2017), “Projeto Livro Telefone Rua" <http://www.marcussiqueira.com/livro-telefone-rual (último acesso em 04/08/2017).

Sloterdijk, Peter (2000), Regras para o parque humano: uma resposta à carta de Heidegger sobre o humanismo, tradução de José Oscar de Almeida Marques, São Paulo, Estação Liberdade.

Tarkos, Christophe (2014), L'enregistré: performances / improvisations / lectures, édition établie et annotée par Philippe Castellin, Paris, P.O.L.

Vasconcelos, Mauricio Salles (2002), "Derivados da diferença - Estenofonia”, in Poéticas da diversidade, organização Marli Fantini Scarpelli, Eduardo de Assis Duarte, Belo Horizonte, UFMG/ FALE.

-- (2015) Exterior. Noite - Filosofia/Literatura, São Paulo, Lumme Editor.

-- (2015a) Jean-Luc Godard: história(s) da literatura, Belo Horizonte, Relicário Edições.

-- (2016) Caderneta-maquete, São Paulo, Córrego. 
-- (2017) Ar livre, São Paulo, Córrego.

-- (2017i) ATO/AMBULANTE, performance apresentada na Biblioteca Roberto Piva, São Paulo, 07/04/2017.

Tiago Cfer é doutorando em Estudos Comparados de Literatura de Língua Portuguesa no Departamento de Letras Clássicas e Vernáculas da Universidade de São Paulo. Traduziu o ensaio Literatura de esquerda, do escritor argentino Damián Tabarovski (lançado no Brasil em maio de 2017 pela editora Relicário). 